\title{
Green Synthesis of Magnetite Nanoparticles using MyrtuscommunisL. Grown in Egypt
}

\author{
*Hesham I. Saleh \\ *Northern Border University, Department of Chemistry, Faculty of science, Arar, Kingdom of Saudi Arabia \\ *National Research Centre, Inorganic Chemistry Department, P.O. 12622, Dokki, Cairo, Egypt
}

\begin{abstract}
Here in, we report, a simple, rapid, and ecofriendly green method was introduced to synthesize magnetite nanoparticles $\left(\mathrm{Fe}_{3} \mathrm{O}_{4}\right.$-NPs $)$ successfully. On treatment of aqueous solutions of ferrous and ferric salts in alkaline medium including MyrtuscommunisL. (MCL) leaf extract with large surface areas ranging from 127 to $318 \mathrm{~m}^{2} \mathrm{~g}-1$, the rapid formation of stable magnetite nanoparticles $\left(\mathrm{Fe}_{3} \mathrm{O}_{4}\right.$-NPs $)$ is observed to occur. MyrtuscommunisL. Leaves (MCL) extract was used as a reducing and stabilizing agent. It was found that the presence of various biomolecules such as flavonoids and terpenoids of the aqueous leaf extract plays a major role for the formation of $\mathrm{Fe}_{3} \mathrm{O}_{4}$-NPs through infrared spectra analysis. X-Ray Diffraction (XRD) and Energy dispersed spectroscopy (EDS) analysis revealed the purity of synthesized $\mathrm{Fe}_{3} \mathrm{O}_{4}$-NPs with crystalline cubic structure phase. Transmission Electron Microscopy (TEM) results illustrated that the size and diameter was in the range from 10 - $12 \mathrm{~nm}$ which agrees with calculated Scherrer equation with average diameter of around $9 \mathrm{~nm}$. Vibrating Sample Magnetometer (VSM) analysis indicated that the samples exhibit super paramagnetic with magnetization value was in the range from 58-72emu/g.
\end{abstract}

Keywords: Biosynthesis, $\mathrm{Fe}_{3} \mathrm{O}_{4}$-NPs, MyrtuscommunisL., XRD, FTIR, TEM, SEM, EDX, BET.

\section{INTRODUCTION}

During recent years, researches on magnetite nanoparticles (MNPs) have been widely developed. MNPs were reported to have some advantages in biocompatibility, biodegradability [1,2], and easily encapsulated [3]. MNPs are used in various application such as catalyst [4], biosensor $[5,6]$, magnetic resonance imaging (MRI) $[7,8]$ and targeted drug delivery $[9$,$] .$

Numerous methods have been reported for synthesis of $\mathrm{Fe}_{3} \mathrm{O}_{4}$ NPs such as co-precipitation, thermal decomposition of organic iron precursor, sol-gel method, Polyol method, surfactant- or polymer-assisted precipitation including reverse micelle, co-polymer templates assisted-synthesis, solvo thermal synthesis and hydrothermal synthesis [10-15]. All these synthetic methods have employed the different chemicals reducing agents and also they are highly reactive and have both biological and environmental negative effects. Therefore, it is highly desirable to prepare $\mathrm{Fe}_{3} \mathrm{O}_{4}$ NPs via green synthesis approach using non-toxic, environmentally benign materials, which offers numerous benefits of ecofriendliness and compatibility for pharmaceutical, biotechnological and biological applications [16].

More recently, plant-mediated green synthesis of nanoparticles has attracted much attention due to cost effective, environmentally friendly alternative to chemical and physical methods. There are successful reports for plantmediated synthesis of $\mathrm{Fe}_{3} \mathrm{O}_{4} \mathrm{NPs}$ using various plant extracts such as seed extract of Grape proanthocyanidin [17], leaf extract of Tridaxprocumbens [18], Orange Peel Extract [19], Sidacordifolia plant extract [20], leaves extract of FraxinuschinensisRoxb [21], and Banana Leaves [22]. However, no literature reports are available for the synthesis of $\mathrm{Fe}_{3} \mathrm{O}_{4}$ NPs using aqueous leaves extract of Myrtuscommunis L. (MCL), .

Myrtuscommunis L.is known as a medicinal plant to antihyperglycemic [23], antiseptic and anti-inflammatory activities [24,25]. It's considering a native plant of the Mediterranean and Asia such as Turkey, Iraq, Iran, and Syria. Different parts of the plant find various uses in food and cosmetic industries [26], such as leaves of Myrtle have been used as a substitute in beer [27], while the drinks prepared from myrtle berries became popular especially in Sardinia [28]. Many references mention myrtle plant in ancient Egyptian medical texts as to remove mucus from the chest, a remedy for urinary disorders, pain, heartburn, swelling, stiffness of the limbs and cough also in Coptic medicine, the essential oil of myrtle was used in a prescription with fresh rue and a mineral for a number of skin disease [29]. In previous study, Myrtuscommunisleaf extract (MCL) was reported contains alkaloids and flavonoids [30]. Alkaloids as a weak base are needed in MNPs preparation, and flavonoids have hydroxil group to prevent MNPs agglomeration [31]. Both of functional materials are contained in MCL as base source and capping agents. Therefore, this research is important in MNPs synthesis, which is not reported in previous study yet. In the 
present study, cost-effective green synthesis of $\mathrm{Fe}_{3} \mathrm{O}_{4} \mathrm{NPs}$ using Myrtuscommunis L. aqueous extract as a capping agent and their characterization using various techniques are reported.

\section{MATERIALS AND METHODS}

\subsection{Materials}

High pure chemicals of Ferric chloride hexahydrate $\left(\mathrm{FeCl}_{3} \cdot 6 \mathrm{H}_{2} \mathrm{O}\right)$ and ferrous chloride tetrahydrate $\left(\mathrm{FeCl}_{2} \cdot 4 \mathrm{H}_{2} \mathrm{O}\right)$ were obtained from Merck (Darmstadt, Germany). Ammonium hydroxide was purchased from El Naser Chemical Ltd; Egypt. Distilled water is also used for preparation of the solutions. MyrtuscommunisL. leaves (MCL), were collected from El-Orman garden, Giza, Egypt.

\subsection{Preparation of Plant Extract}

The fresh leaves of MyrtuscommunisL. (MCL) were air dried, powdered and stored in the absence of light for further experimental use. A total of $50 \mathrm{~g}$ of MCL was placed in a separate $500 \mathrm{~mL}$ conical flasks with $250 \mathrm{~mL}$ of double distilled water and boiled for $15 \mathrm{~min}$ with continuous stirring. The boiled extract solution was allowed to cool to room temperature, and stored at $4^{\circ} \mathrm{C}$ in a tight glass bottle for further synthesis of $\mathrm{Fe}_{3} \mathrm{O}_{4} \mathrm{NPs}[32]$.

\subsection{Synthesis of magnetic $\mathrm{Fe}_{3} \mathrm{O}_{4} \mathrm{NPs}$}

The process was carried out in a $500 \mathrm{~mL}$ jacketed glass reactor equipped with a reflux condenser, mechanical agitation (400 rpm), and an inlet for the feed of ammonium hydroxide $\left(\mathrm{NH}_{4} \mathrm{OH}, 25 \%\right)$. The procedure started with mixing in the reactor $50 \mathrm{~mL}$ of $\mathrm{FeCl}_{3} \cdot 6 \mathrm{H}_{2} \mathrm{O}(0.32 \mathrm{M})$ and $50 \mathrm{~mL}$ of $\mathrm{FeCl}_{2} .4 \mathrm{H}_{2} \mathrm{O}(0.2 \mathrm{M})$ in $200 \mathrm{~mL}$ of distilled water. Then, the required amount of $\mathrm{MCL}$ was added to the reaction mixture, raising the mixture temperature to $80^{\circ} \mathrm{C}$.

Three concentrations of MCL were used: 20, 30, and 40 (v/v).Magnetic $\mathrm{Fe}_{3} \mathrm{O}_{4}$ NPs prepared with three different volumes 20,30, and 40 (v/v) of MCL were named S1, S2 and S3 sequentially. Co-precipitation reaction without MCL was also carried out as a control. Once $\mathrm{Fe}^{+2}, \mathrm{Fe}^{+3}$, and $\mathrm{MCL}$ solution reached the desired temperature $\left(80{ }^{\circ} \mathrm{C}\right)$, the dosing of $20 \mathrm{~mL}$ of the ammonium hydroxide at $0.67 \mathrm{~mL} / \mathrm{min}$ was started to permit uniform precipitation of magnetite in the reaction mixture. After dosing was over, the reaction solution was stirred at $80^{\circ} \mathrm{C}$ for another 2 hours. For separation of the MNPs from the aqueous solution, a magnetic field was used and the resulting MNPs were washed with deionized water, and dried in a hot air-dry oven and stored in airtight bottles at room temperature for further characterization.

\section{EXPERIMENTAL SET-UP}

X-ray diffraction (XRD, Rigaku Rint 2000 Ultima III, Japan) with $\mathrm{Cu}-\mathrm{K} \alpha$ radiation $(=0.15406 \mathrm{~nm})$ was used to determine the crystal structure of the $\mathrm{Fe}_{3} \mathrm{O}_{4}$ samples and the mean crystallite size of nanoparticles were calculated by Scherrer's equation using XRD data $[33,34]$. The Fourier transform infrared spectroscopy (FTIR, IR-Prestige-21 Shimadzu) analysis was performed at room temperature using the transmittance mode in the frequency range of $400-4000$ $\mathrm{cm}^{-1}$. The FTIR sample preparation was done by mixing the $\mathrm{Fe}_{3} \mathrm{O}_{4}$ sample with potassium bromide ( $\mathrm{KBr}$ ) followed by compression to form pellets for the measurements. SEM (TESCAN- MAIA3 XMU) and their quantitative analysis were carried out by using energy dispersive spectroscopy (EDS) attached to SEM. The specific surface areas of the asprepared $\mathrm{Fe}_{3} \mathrm{O}_{4}$ samples were measured using the BrunauerEmmett- Teller (BET) method, after being degassed at $100{ }^{\circ} \mathrm{C}$ for $12 \mathrm{~h}$ (Belsorp-mini II Sorption System, BEL Japan, Inc.). Finally, the magnetic properties of the $\mathrm{Fe}_{3} \mathrm{O}_{4}$ samples were characterized using a vibrating sample magnetometer (VSM, PPMS-6000, and USA) at room temperature.

\section{RESULT AND DISCUSSION}

\subsection{X-ray Diffraction}

XRD patterns shown in Fig. 1 are utilized to demonstrate the crystal structure of the synthesized nanoparticle samples, S1 (Fig. 1a), S2 (Fig. 1b), and S3 (Fig. 1c). The measured diffraction angles of all samples show a good consistency with those from standard XRD pattern of magnetite $\left(\mathrm{Fe}_{3} \mathrm{O}_{4}, \mathrm{PDF}\right.$ card No. 11-614) [35] with five pronounced peaks, appearing at $30.09^{\circ}, 35.42^{\circ}, 43.05^{\circ}, 56.94^{\circ}$, and $62.51^{\circ}$ correspondingly to (200), (311), (400), (511), and (440) lattices of magnetite crystalline structure.

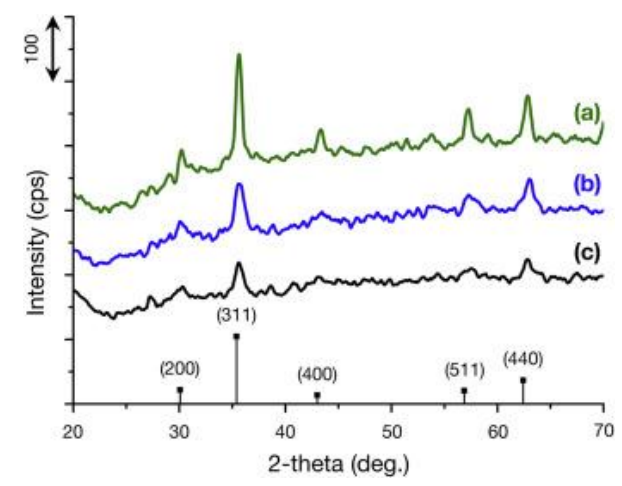

Figure 1: XRD patterns of (a) sample S1, (b) sample S2, and (c) sample S3

The inter planar spacing, calculated by Bragg's Law [36] and referenced as shown in Table 1, indicate that all samples possess the inverse cubic spinal structure of magnetite with over $95 \%$ being consistent with the referenced date. 
ISSN (online): 2581-3048

Table 1: Comparison of the interplanar spacing of sample S1, sample S2 and sample S3 to the standard data of magnetite (Fe $\mathrm{O}_{4}$, JCPDS No. 11-614)

\begin{tabular}{|c|c|c|c|c|c|}
\hline hkl & 200 & 311 & 400 & 511 & 440 \\
\hline Standard $2 \theta$ & 30.09 & 35.42 & 43.05 & 56.94 & 62.51 \\
\hline $\mathrm{d}(\AA)$ & 2.967 & 2.532 & 2.099 & 1.616 & 1.484 \\
\hline S1 & 32.22 & 35.64 & 43.34 & 57.26 & 62.86 \\
\hline $\mathrm{d}(\AA)$ & 2.776 & 2.517 & 2.086 & 1.608 & 1.477 \\
\hline Completeness (\%) & 95.36 & 99.41 & 99.38 & 99.48 & 99.54 \\
\hline $2 \theta$ & 30.08 & 35.60 & 43.44 & 57.26 & 63.00 \\
\hline $\mathrm{d}(\AA)$ & 2.968 & 2.519 & 2.081 & 1.608 & 1.474 \\
\hline Completeness (\%) & 99.95 & 99.52 & 99.17 & 99.48 & 99.34 \\
\hline $\mathrm{S} 3$ & 30.32 & 35.60 & 43.10 & 57.58 & 62.80 \\
\hline $\mathrm{d}(\AA)$ & 2.945 & 2.519 & 2.097 & 1.599 & 1.478 \\
\hline Completeness (\%) & 99.28 & 99.52 & 99.91 & 98.98 & 99.63 \\
\hline
\end{tabular}

The average crystalline size of magnetite nanoparticles in S1, S2, and S3 samples, estimated from Scherrer's equation with full-width at half-maximum values obtained from the corresponding strongest peaks (311), are $27 \mathrm{~nm}, 9 \mathrm{~nm}$, and 9 nm, respectively.

In addition, XRD patterns of sample S2 and sample S3 appearing with lower intensities and broader reflections could be referred to the decrease of crystallite size of the nanoparticles, leading to the X-rays being more strongly and widely diffused than the one observed from sample S1 [37].

\subsection{Transmission Electron Microscope (TEM)}

TEM images shown in Fig. 2 reveal the morphology and size distribution of as-prepared nanoparticles. Sample S1 (Fig. $2 \mathrm{a}$ and $\mathrm{b}$ ) appears with an unidentified morphology, widely distributing from tens to hundreds nanometers. Whilst, sample S2 (Fig. 2c and d) and sample S3 (Fig. 2e and f) likely comprise homogenously spherical nanoparticles with the average diameter ca.10 nm, in form of tightly nanoparticle aggregates.

The particle size agrees with that calculated from Scherrer equation with average diameter of around $9 \mathrm{~nm}$. The good correlation between particle sizes obtained from Scherrer equation and TEM supports the crystalline structure of the $\mathrm{Fe}_{3} \mathrm{O}_{4}$ nanoparticles. The upper bound on particle sizes, in comparing with the calculations from XRD analysis, could be explained by inhomogeneous strain and crystal lattice imperfections on the surface of the nanoparticles, leading to smaller calculated values in Scherrer's equation [38].
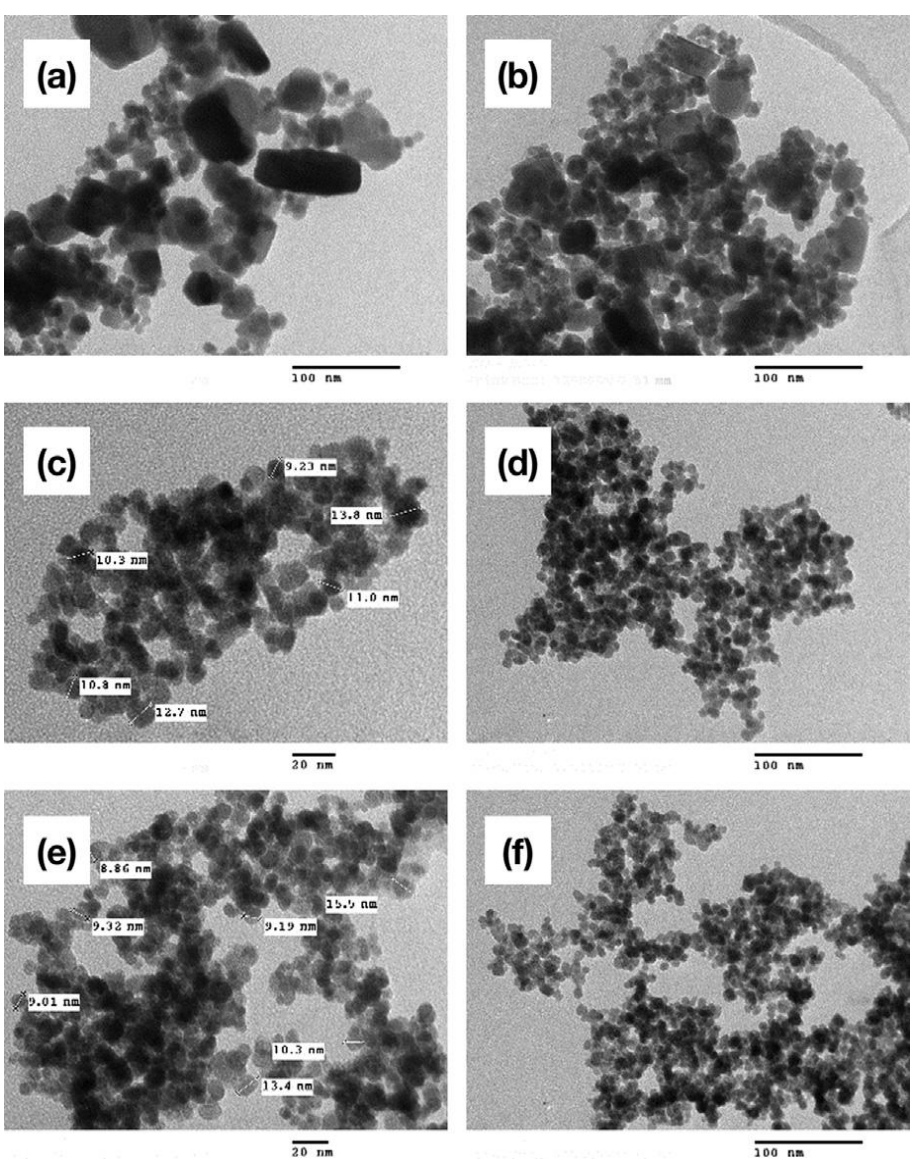

Figure 2: TEM images of (a, b) sample S1, (c, d) sample S2, and (e, f) sample S3

Therefore the magnetite nanoparticles were successfully synthesized by this green method using MCL leaf extract as reducing agent and stabilizer for nanoparticles. 
ISSN (online): 2581-3048

\subsection{The Study of Vibrating Sample Magnetometer (VSM)}

Fig. 3 represents the room-temperature $\mathrm{M}-\mathrm{H}$ curves of as prepared magnetite samples, measured by cycling the external magnetic field between - 11,000 Oe and 11,000 Oe. All samples, S1 (Fig. 3a), S2 (Fig. 3b), and S3 (Fig. 3c) exhibit soft magnetic characteristic with large saturation magnetization (Ms) values of 72.5 emu.g ${ }^{-1}, 67.7 \mathrm{emu}^{-\mathrm{g}^{-1}}$, and 57.7 emu.g $^{-1}$, respectively, which equal to the sum of the magnetic moments in each cluster of magnetite nanoparticles[39]. Whilst, the obtained coercive field (Hc) values are considerably distinguishable, with 75 Oe, 25 Oe, and 5 Oe respectively according to coercivities of sample S1, sample S2, and sample S3.

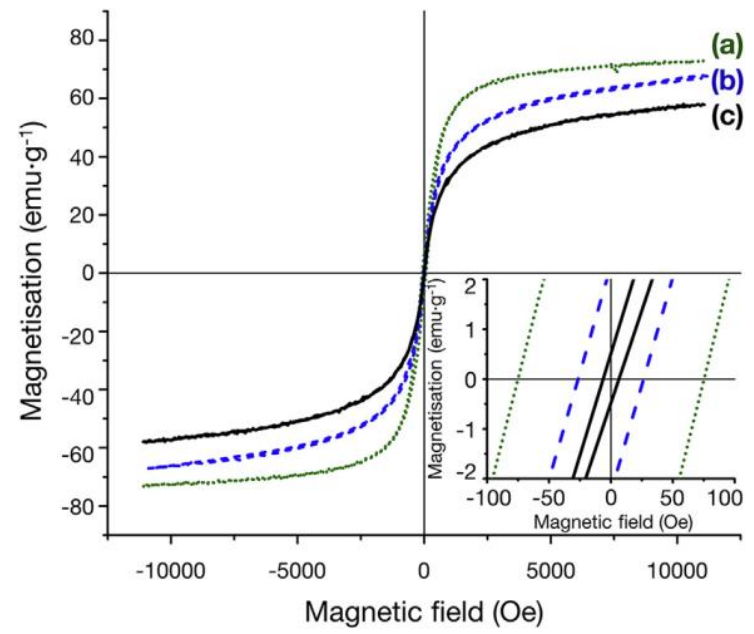

Figure 3: M-H curves of (a) sample S1, (b) sample S2, and (c) sample S3

The hysteresis loop of the nanoparticles, which was measured in the powder state, is shown in Figure 4 which provided evidence that all the MNPs were super paramagnetic at room temperature, with no hysteresis. This super paramagnetic property of the magnetic nanoparticles makes them very susceptible to magnetic field and, therefore, the nanoparticles separate easily from solution. Without the external field, the nanoscale magnetic will not show any magnetic properties toward outside. The magnetizations of MCL-Fe3O4 NPs were ranging from 57.7 to $72.5 \mathrm{emu} / \mathrm{g}$ which is less than that of the actual magnetization of the $\mathrm{Fe}_{3} \mathrm{O}_{4}$ is $92 \mathrm{emu} / \mathrm{g}$ [40]. The decrease of the saturation is ascribed to the size effect in which the smaller the size of the nanoparticles, the lower the saturation magnetization value. The saturation magnetization $(M s)$ of the $\mathrm{Fe}_{3} \mathrm{O}_{4}$ indicates the presence of non-magnetic surface layers resulting from the strong chemical attachment of the stabilizing agent of MCL leaf extract to the $\mathrm{Fe}_{3} \mathrm{O}_{4}$ 's surface, which also observed by FTIR spectroscopy. Finally, the recorded hysteresis loops showed that the particles are super paramagnetic at room temperature, which is characteristic of a soft ferromagnetic material such as magnetite [41].

\subsection{Surface Area Values for Synthesized Magnetic $\mathrm{Fe}_{3} \mathrm{O}_{4}$ NPs}

Nitrogen adsorption-desorption isotherms were employed to determine the surface areas of samples S1, S2, and S3 and to identify the trend in surface area with increasing MCL content. The specific surface areas of the $\mathrm{Fe}_{3} \mathrm{O}_{4}$ samples were determined by the Brunauer-Emmett-Teller (BET) method, as depicted in Figure 4.
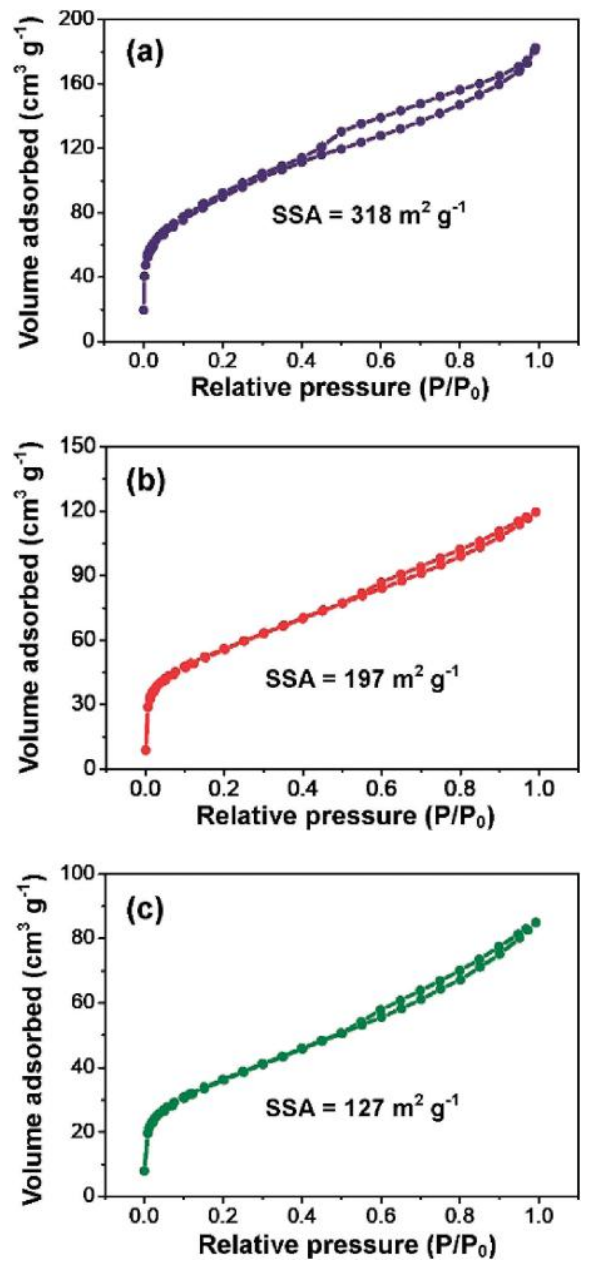

Figure 4: Nitrogen adsorption-desorption isotherms of $\mathrm{Fe} 3 \mathrm{O} 4$ samples: (a) S1, (b) S2, and (c) $\mathrm{S3}$

The specific surface areas of samples S1, S2, and S3 were measured to be 318,197 , and $127 \mathrm{~m} 2 \mathrm{~g} 11$, respectively. Furthermore, the total pore volumes of samples S1, S2, and S3 were determined to be $0.241,0.163$, and $0.119 \mathrm{~cm}^{3} \mathrm{~g}^{-1}$, respectively. The decrease in both surface area and pore volume of the obtained $\mathrm{Fe}_{3} \mathrm{O}_{4}$ products with increasing MCL content is largely due to the increased aggregation among the nanoparticles, as evident in Figure 2.

\subsection{FTIR Spectral Analysis}

The FTIR spectra of aqueous leaf extract of MCL and $\mathrm{Fe}_{3} \mathrm{O}_{4}$ NPs (S3) were presented in Figure 5. 


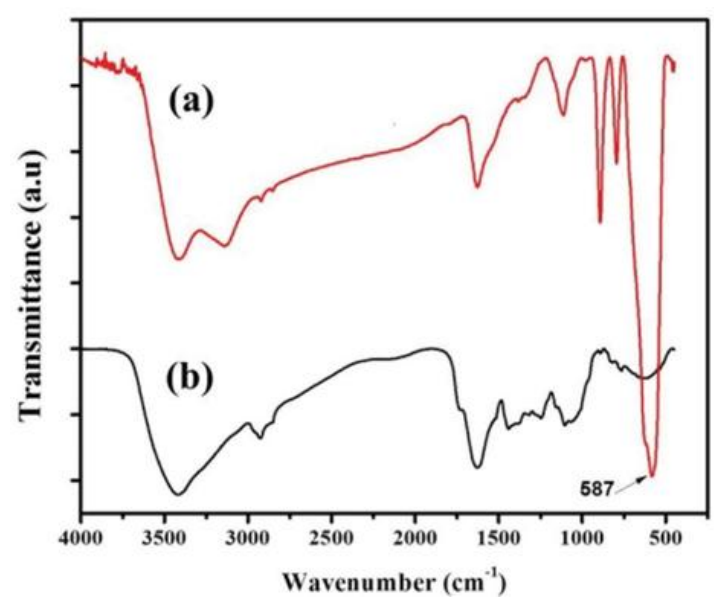

Figure 5: FTIR spectra of (a) Fe304 NPs synthesized using aqueous leaf extract of MCL (S3) and (b) aqueous leaf extract of MCL

The FTIR spectrum of the aqueous leaf extract of MCL (Figure 5 (a)), exhibited characteristic bands at 3417, 2925, 1631, 1441, 1243, 1105 and $617 \mathrm{~cm}^{-1}$. The bands at 3417 , 2925,1631 and $1441 \mathrm{~cm}^{-1}$ are ascribed to the presence of $\mathrm{O}-\mathrm{H}$ group of phenolic compound, $\mathrm{C}-\mathrm{H}$ group of alkane, $\mathrm{C}=\mathrm{O}$ group of carboxylic acids, and $\mathrm{C}=\mathrm{C}$ group of aromatic compound, respectively. In case of $\mathrm{Fe}_{3} \mathrm{O}_{4}$ NPs (Figure 5 (b)), the characteristic band due to $\mathrm{O}-\mathrm{H}$ group of phenol shifted from 3417 to $3408 \mathrm{~cm}^{-1}$ indicating that $\mathrm{O}-\mathrm{H}$ group of phenol acts as reducing agent in the formation of $\mathrm{Fe}_{3} \mathrm{O}_{4} \mathrm{NPs}$. The band due to $\mathrm{C}=\mathrm{O}$ group of carboxylic acid $\left(1631-1626 \mathrm{~cm}^{-1}\right)$, the bands associated to $\mathrm{C}=\mathrm{C}$ group of aromatic compounds (1441- $1401 \mathrm{~cm}^{-1}$ ) and also $\mathrm{C}-\mathrm{O}$ stretching frequency of phenolic group (1105-1130 $\mathrm{cm}^{-1}$ ) were shifted compared to aqueous leaf extract of MCL indicating that the carboxyl group $(-\mathrm{COOH})$ present in leaf extract acts as capping agent for $\mathrm{Fe}_{3} \mathrm{O}_{4} \mathrm{NPs}$. The strong additional band at $587 \mathrm{~cm}^{-1}$ was observed for $\mathrm{Fe}_{3} \mathrm{O}_{4}$ NPs which is ascribed to the stretching vibration of $\mathrm{Fe}-\mathrm{O}[42,43]$. FTIR spectrum indicates that the phyto constituents present in aqueous leaf extract of MCL were efficiently acting as reducing and capping agent for the formation of $\mathrm{Fe}_{3} \mathrm{O}_{4}$ NPs [44].

\subsection{Scanning Electron Microscopy}

Figure 6(a) depicts the SEM image of $\mathrm{Fe}_{3} \mathrm{O}_{4}$ nanoparticles prepared from aqueous leaf extract of MCL (S3). Magnetite nanoparticles exhibit cubic and almost spherical structures with nearly equal to $9 \mathrm{~nm}$ particle size.

The prepared nanoparticles were not agglomerated even though capping agents are not used [45]. The MCL extract itself acts as a natural capping agent due to the presence of a large number of photochemical in the leaf. The prepared flower extract also exhibits a strong reducing power due to the presence of more amount of phenolic and flavonoid compounds; as a result of which $\mathrm{Fe}^{3+}$ in the precursor reduced to $\mathrm{Fe}^{2+}$ effectively $[46,47]$. Therefore, this method is very much environmentally friendly, simple and cost-effective.

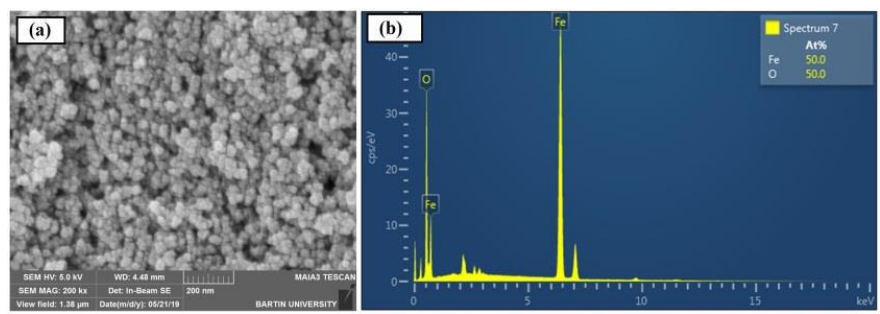

Figure 6: (a) $\mathrm{SEM}$ image of $\mathrm{Fe}_{3} \mathrm{O}_{4}$ nanoparticles (S3) (b) Energy dispersed spectroscopy (EDS) image of $\mathrm{Fe}_{3} \mathrm{O}_{4}$ nanoparticles prepared by aqueous leaf extract of $M C L(S 3)$

The qualitative and quantitative elemental analysis of prepared $\mathrm{Fe}_{3} \mathrm{O}_{4}$ nanoparticles were carried out using EDS. Figure 6(b) represents the EDS image and elemental composition of magnetite nanoparticles prepared from aqueous leaf extract of MCL (S3). Both iron and oxygen atoms present in prepared $\mathrm{Fe}_{3} \mathrm{O}_{4}$ nanoparticles are stoichiometric to each other and agree with the theoretical and experimental values.

\section{CONCLUSION}

In conclusion, the $\mathrm{Fe}_{3} \mathrm{O}_{4}$ NPs was successfully synthesized using aqueous leaf extract of MyrtuscommunisL. (MCL) via green route method. The photochemical present in aqueous leaf extract of MyrtuscommunisL. (MCL) can act as reducing and capping agent for the formation of $\mathrm{Fe}_{3} \mathrm{O}_{4} \mathrm{NPs}$. The spherical morphology was observed for $\mathrm{Fe}_{3} \mathrm{O}_{4} \mathrm{NPs}$ with average particle size of $10 \mathrm{~nm}$. The room temperature magnetization curve reveals superparamagnetic behavior of $\mathrm{Fe}_{3} \mathrm{O}_{4}$ NPs.

\section{REFERENCES}

[1] Bo-Wei Chen, Yun-Chi He, Shian-Ying Sung, TrangThi Huynh Le, Chia-Ling Hsieh, Jiann-Yeu Chen, Zung-Hang Wei \& Da-Jeng Yao. "Synthesis and characterization of magnetic nanoparticles coated with polystyrene sulfonic acid for biomedical applications". Science and Technology of Advanced Materials, Vol. 21(1), pp. 471-481, 2020. https://doi.org/10.1080/14686996.2020.1790032

[2] Azizi S, Nosrati H, Danafar H. "Simple surface functionalization of magnetic nanoparticles with methotrexate conjugated bovine serum albumin as a biocompatible drug delivery vehicle". Appl Organometal Chem. 2020; e5479. https://doi.org/10. 1002/aoc.5479

[3] Shabatina, T. I., Vernaya, O. I., Shabatin, V. P., \&Melnikov, M. Y. "Magnetic Nanoparticles for Biomedical Purposes: Modern Trends and Prospects" 
Magnetochemistry, 6(3), 30, 2020. Doi: 10.3390/magnetochemistry6030030

[4] Asmaa Mohamed El Shafey. "Green synthesis of metal and metal oxide nanoparticles from plant leaf extracts". Green Processing and Synthesis, 9: 304339,2020. https://doi.org/10.1515/gps-2020-0031

[5] Su, Wu, Saha, Peng, \& Wang. "Advances in Magnetoresistive Biosensors". Micromachines, 11(1), 34, 2019. doi:10.3390/mi11010034

[6] Kumar, V., \& Arora, K. "Trends in Nano-inspired Biosensors for Plants". Materials Science for Energy Technologies. 3, 255273.2020. doi:10.1016/j.mset.2019.10.004

[7] Nikhil Pandey, Jyothi U. Menon, Masaya Takahashi, Jer-Tsong Hsieh, Jian Yang, Kytai T. Nguyen, Aniket S. Wadajkar. "Thermo-responsive Fluorescent Nanoparticles for Multimodal Imaging and Treatment of Cancers", Nanotheranostics, 4(1): 1-13, 2020. doi: 10.7150/ntno.39810

[8] Ali Yadollahpour, Halime Mansoury Asland Samaneh Rashidi."Applications of Nanoparticles in Magnetic Resonance Imaging: A Comprehensive Review". Asian Journal of Pharmaceutics, 11(1):S7S13, 2017.

[9] Mou, X., Ali, Z., Li, S., \& He, N. "Applications of Magnetic: Nanoparticles in Targeted Drug Delivery System" Journal of Nanoscience and Nanotechnology.15 (1), 5462,2015.doi:10.1166/jnn.2015.9585

[10] Nguyen, C. T., Kim, C. R., Le, T. H., Koo, K., \& Hwang, C. H. "Magnetically guided targeted delivery of erythropoietin using magnetic nanoparticles". Medicine. 99(19), e19972, 2020. doi:10.1097/md.0000000000019972

[11] Majidi, S., ZeinaliSehrig, F., Farkhani, S. M., Soleymani Goloujeh, M., \& Akbarzadeh, A. "Current methods for synthesis of magnetic nanoparticles", Artificial Cells Nanomedicine and Biotechnology, 44(2), 722-734, 2014. doi:10.3109/21691401.2014.982802

[12] Belachew N, Rama Devi D, Basavaiah K. "Facile green synthesis of L-methionine capped magnetite nanoparticles for adsorption of pollutant Rhodamine B”. J Mol Liq.; 224:713-720, 2016.

[13] Zhang W, Shen F, Hong R. "Solvothermal synthesis

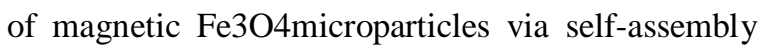
of Fe3O4 nanoparticles". Particuology, 9:179-186, 2011.

[14] Ahmadi S, Chia C-H, Zakaria S, et al. "Synthesis of Fe3O4nanocrystals using hydrothermal approach". $J$ MagnMagn Mater. 324:4147-4150, 2012.
[15] Nguyen, T. L., Nizamov, T. R., Abakumov, M. A., Shchetinin, I. V., Savchenko, A. G., \&Majouga, A. G. "Effect of Magnetite Nanoparticle Morphology on the Parameters of MRI Relaxivity". Bulletin of the Russian Academy of Sciences: Physics, 82(9), 12141221, 2018.

[16] Oxana V. Kharissova1, H.V. Rasika Dias, Boris I. Kharisov, Betsabee Olvera Pe'rez, and Victor M. Jime'nezPe'rez. "The greener synthesis of nanoparticles". Trends Biotechnol, 31:240-248, 2013.

[17] Liu, M., Yun, P., Hu, Y., Yang, J., Khadka, R. B., \&Peng, X. "Effects of Grape Seed Proanthocyanidin Extract on Obesity". Obesity Facts, 1-13, 2020. Doi: 10.1159/000502235

[18] Yasodha T, Jeevitha, Yogesh, Ramanan. "Efficiency of phytobiotics of Indian medicinal plant Tridaxprocumbens L. against wound infecting bacteria". MOJ Research Review. 1(6):278-280, 2018. DOI: 10.15406/mojcrr.2018.01.00046

[19] Mohsan Bashir, Shaista Ali and Muhammad Akhyar Farrukh. "Green Synthesis of $\mathrm{Fe}_{2} \mathrm{O}_{3}$ Nanoparticles from Orange Peel Extract and a Study of Its Antibacterial Activity". Journal of the Korean Physical Society, Vol. 76, (9), pp. 848-854, 2020.

[20] Pallela, P. N. V. K., Ummey, S., Ruddaraju, L. K., Gadi, S., Cherukuri, C. S., Barla, S., \& Pammi, S. V. N. "Antibacterial efficacy of green synthesized $\alpha$ $\mathrm{Fe}_{2} \mathrm{O}_{3}$ nanoparticles using Sidacordifolia plantextract". Heliyon, 5(11), e02765, 2019. doi:10.1016/j.heliyon.2019.e02765

[21] Ali, I., Peng, C., Lin, D., \& Naz, I. "Green synthesis of the innovative super paramagnetic nanoparticles from the leaves extract of Fraxinuschinensis Roxb and their application for the decolourisation of toxic dyes". Green Process Synth, 8: 256-271, 2019. doi:10.1515/gps-2018-0078

[22] Ravindra D. Kale, Sangeeta Barwar, Prerana Kane and Latika Bhatt. "Green Synthesis of Magnetite Nanoparticles using Banana Leaves". European Journal of Sciences (EJS), vol.1, (1), pp.26-34, 2018. DOI: $10.29198 /$ ejs 1803

[23] Panjeshahin, M. R., Azadbakht, M., \&Akbari, N. "Antidiabetic Activity of Different Extracts of MyrtusCommunis in Streptozotocin Induced Diabetic Rats".Romanian Journal of Diabetes Nutrition and Metabolic Diseases, 23(2), 2016. doi:10.1515/rjdnmd-2016-0022

[24] Talebianpoor MS, Talebianpoor MS, Mansourian M, Vafaiee-Nejad T. "Antidiabetic activity of hydroalcohoic extract of Myrtuscommunis (myrtle) 
fruits in streptozotocin-induced and dexamethasoneinduced diabetic rats". Phcog Res; 11:115-20, 2019.

[25] Issa IA, Bule MH. "A Comparative Study of the Hypoglycemic Effect of Aqueous and Methanolic Extracts of Myrtuscommunis on Alloxan Induced Diabetic Siwis Albino Mice". Med Aromat Plants 4: 190, 2015. Doi:10.4172/2167-0412.1000190

[26] J. C.Chalchat, R. F. Garry, and A. Michet. "Essential oils of Myrtle (Myrtuscommunis L.) of the Miterranean littoral". Journal of Essential Oil Research, vol. 10, pp. 613-617.1998.

[27] Ebru, K., Murat, G., Saeid, S., Hulya, Y. and Sina, K. "Volatile compounds of selected white and black myrtle (Myrtuscommunis L.) types from Mediterranean region of Turkey". J. Med. Plants Res. Vol. 7(18), pp. 1244-1248, 2013.

[28] F. Nuvoli, and D. Spanu, "Analisie prospettive economic edell'utilizzazion ze industriale del mirto". RivistaItaliana EPPOS, vol. 12, pp. 231-236.1996.

[29] Amots D. and Barbara B. "Medicinal plants of the Bible-revisited". Journal of Ethnobiology and Ethnomedicine, 15:57, 2019.doi.org/10.1186/s13002019-0338-8

[30] E.A. Aboutabl. K.M. Meselhy, E.M. Elkhreisy, M.I.Nassar and R. Fawzi , "Composition and Bioactivity of Essential Oils from Leaves and Fruits of Myrtuscommunis and Eugenia supraxillaris(Myrtaceae) Grown in Egypt". Jeobp 14 (2) ,pp 192 - 200, 2011.

[31] Sari, I. P., \&Yulizar, Y. "Green synthesis of magnetite (Fe3O4) nanoparticles using Graptophyllumpictum leaf aqueous extract". IOP Conference Series: Materials Science and Engineering, 191, 012014, 2017. doi:10.1088/1757899x/191/1/012014

[32] Patra JK, Baek KH. "Novel green synthesis of gold nanoparticles using Citrulluslanatusrind and investigation of proteasome inhibitory activity, antibacterial and antioxidant potentia" $l$. Int $J$ Nanomed. Doi: 10:7253-7264, 2015.

[33] P. Scherrer, Bestimmung der Große und der inneren Struktur von Kolloidteilchenmittels Rontgenstrahlen, Nachrichten von Der Gesellschaft Der Wissenschaften $\mathrm{Zu}$ Gottingen, Math. Klasse 2: 98100, 1918. http://eudml.org/doc/59018

[34] A.L. Patterson, "The Scherrer formula for X-ray particle size determination", Phys. Rev. 56, 978e981, 1939. https://doi.org/10.1103/PhysRev.56.978

[35] H.E. Swanson, M.C. Morris, H.F. McMurdie, E.H. Evans, "Standard X-ray Diffraction Powder Patterns: Section 5, National Bureau of Standards, Washington, D.C., 1967.
[36] W. Wang, B. Tang, B. Ju, S. Zhang, “ Size-controlled synthesis of water-dispersible superparamagnetic $\mathrm{Fe}_{3} \mathrm{O}_{4}$ nanoclusters and their magnetic responsiveness", R. Soc. Chem. 5: 75292-75299, 2015. https://doi.org/10.1039/c5ra14354c

[37] A.K. Singh, "Advanced X-ray Techniques in Research and Industry", IOS Press, 2005.

[38] Z. Zhang, F. Zhou, E.J. Lavernia, "Onthe analysis of grain size in bulk nanocrystalline materials via X-ray diffraction", Metall. Mater. Trans. A-Phys. Metall. Mater. Sci. 34A: 1349-1355, 2003.https://doi.org/10.1007/s11661-003-0246-2

[39] C. Cheng, Y. Wen, X. Xu, H. Gu, "Tunable synthesis of carboxyl-functionalized magnetite nano crystal clusters with uniform size", J. Mater. Chem. 19: 8782-8788, 2009.https://doi.org/10.1039/b910832g

[40] H. M. Lu, W. T. Zheng, and Q. Jiang, "Saturation Magnetization of Ferromagnetic and Ferri magnetic Nanocrystals at Room Tempera-ture”. J. Phys. D. Appl. Phys., vol. 40, no. 2, pp. 320-325, 2007.

[41] Lopez J, González F, Bonilla FA, Zambrano G, Gomez ME. "Synthesis and characterization of $\mathrm{Fe}_{3} \mathrm{O}_{4}$ magnetic nanofluid". Latin Ame J Metallurgy Material. 30:60-66, 2010.

[42] Cornell RM, Schwertmann U. "The iron oxides: structures, properties, reactions, occurrences and uses", Weinheim: Wiley-VCH, 2003.

[43] Y. T. Prabhu, K. V. Rao, B. S. Kumari, V. S. S. Kumar, and T. Pavani, "Synthesis of Fe3O4 nanoparticles and its antibacterial application," International Nano Letters, vol. 5, ( 2), 85-92, 2015.

[44] Alam F, Saqib QU. "Pharmacognostic study and development of quality control parameters for fruit, bark and leaf of Zanthoxylumarmatum (Rutaceae)". Anc Sci Life. 34:147, 2015.

[45] Shashanka, R.; Swamy, B.E.K. "Biosynthesis of silver nanoparticles using leaves of Acacia melanoxylon and its application as dopamine and hydrogen peroxide sensors". Physical Chemistry Research, 8, 1-18, 2020.

[46] Karimi, E.; Oskoueian, E.; Hendra, R.; Jaafar, H.Z.E. "Evaluation of Crocus Sativus L. Stigma Phenolic and Flavonoid, Compounds and Its Antioxidant Activity". Molecules, 15, 62446256,2010.https://doi.org/10.3390/molecules 1509624 4

[47] Siddhuraju, P.; Becker, K. "Antioxidant properties of various solvent extracts of total phenolic constituents from three different agroclimatic origins of drumstick tree (Moringaoleifera Lam.) leaves". J Agric Food Chem. 51: 2144-2155, 2003. https://doi.org/10.1021/jf020444 
Citation of this Article:

Hesham I. Saleh, "Green Synthesis of Magnetite Nanoparticles using MyrtuscommunisL. Grown in Egypt" Published in International Research Journal of Innovations in Engineering and Technology - IRJIET, Volume 4, Issue 9, pp 6-13, September 2020. https://doi.org/10.47001/IRJIET/2020.409002

$* * * * * * *$ 